\title{
Publisher Correction: Roux-en-Y Gastric Bypass in Patients with Super Obesity: Primary Response Criteria and Their Relationship with Comorbidities Remission
}

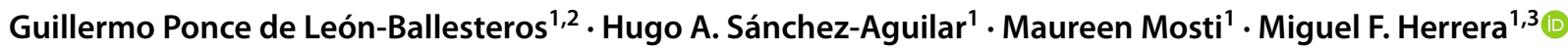

Published online: 14 February 2022

(c) The Author(s), under exclusive licence to Springer Science+Business Media, LLC, part of Springer Nature 2022

Publisher Correction: Obesity Surgery

https://doi.org/10.1007/s11695-021-05862-4

This manuscript was accepted for publication. However, the term "superobesity" (BMI $>50 \mathrm{~kg} / \mathrm{m}^{2}$ ) is not considered by the leadership of IFSO to be an acceptable term.

Acceptable alternatives include "BMI $>50 \mathrm{~kg} / \mathrm{m}^{2}$ " or "severe obesity."

Publisher's Note Springer Nature remains neutral with regard to jurisdictional claims in published maps and institutional affiliations.

The original article can be found online at https://doi.org/10.1007/ s11695-021-05862-4

Miguel F. Herrera

miguelfherrera@gmail.com

1 Clinic for Nutrition and Obesity, ABC Medical Center, Mexico City, Mexico

2 Centro de Investigación en Ciencias de La Salud (CICSA), Facultad de Ciencias de la Salud, Universidad Anáhuac Norte, Lomas Anahuac, Mexico

3 Department of Surgery, Instituto Nacional de Ciencias Médicas Y Nutrición Salvador Zubirán, Mexico City, Mexico 